\title{
Evaluation of variation in dose of organs at risk in intracavitary brachytherapy of cervical cancer - a prospective study
}

\author{
Brahmacharimayum Arunkumar Sharma, PhD, Th. Tomcha Singh, MD, L. Jaichand Singh, MD
}

Department of Radiotherapy, Regional Cancer Centre, Regional Institute of Medical Sciences, Imphal, India

\begin{abstract}
Purpose: The aim of this work was to evaluate the variation of dose in organs at risk (OARs) in fractionated high dose rate intracavitary brachytherapy (HDR-BT) for cervical cancer.

Material and methods: A prospective study was carried out on 20 cervical cancer patients treated with fractionated (HDR-BT). International Commission on Radiation Units and Measurement (ICRU) bladder (bICRU) and rectum (rICRU) points were defined according to ICRU Report 38, using two orthogonal radiograph images taken by Simulator (Simulix $\mathrm{HQ}^{\circledR}$ ) and prospectively kept to less than $80 \%$ of prescription dose to point A during real treatment planning process using the Plato Sunrise Treatment Planning System ${ }^{\circledR}$.

Results: The average variation of individuals in estimated doses of OARs in the inter fractional as well as in a single fraction were $2.4 \%$ and $0.7 \%$ of point $\mathrm{A}$ for rICRU, $4.3 \%$ and $1.6 \%$ for bICRU, and $0.8 \%$ \& $0.2 \%$ for point $\mathrm{B}$, whereas point A itself was found to be $1.6 \%$ \& $0.6 \%$.

Conclusions: Average variation of the delivery of dose per fraction was found well within the recommended limit. The study observed smaller variation of doses to OARs which could present better reproducibility of geometry of (HDR-BT) applicators and its relative displacement with critical structures. Transportation of patient from simulator room to treatment room causes small uncertainties in delivery dose.

Key words: HDR brachytherapy, cervical cancer, ICRU, rectum, bladder.

\section{Purpose}

The result of treatment of cervical cancer is greatly enhanced by the use of intracavitary brachytherapy [1-4]. Brachytherapy is normally used either alone or, more commonly, as a part of a multi-modality approach with external beam radiation therapy (EBRT), surgery, and/or chemotherapy. The American Brachytherapy Society (ABS) strongly recommends that radiation treatment for cervical cancer (with or without chemotherapy) should include brachytherapy as a component of treatment [5]. Rectal and bladder doses in HDR-BT for cervical cancer are estimated using the International Commission on Radiation Unit and Measurement (ICRU) reference points [6]. The ABS recommends to displace the bladder and rectum from the applicator using an in-built rectal retractor, radiopaque gauze, a posterior vaginal speculum blade, or an inflatable catheter bulb to increase the therapeutic ratio [5]. The insertion of the rectal retractors may actually transfer the applicators towards the bladder, making anterior vaginal packing even more significant. They also recommend the use of external fixation devices to help prevent applicator movement.
Many institutions carry out the treatment of cervical cancer with the use of HDR-BT in 2-7 fractions as a part of their treatment protocol $[7,8]$. Using imaging equipment, the applicator position is kept nearly identical to the first fraction to obtain the treatment planning and dosimetry. In many institutions, an integrated brachytherapy unit (IBU) is not available where imager is in-built with the treatment unit. Therefore, the options include transferring patients either from the operating room or a procedure room in the department, to the simulator for radiograph generation and then transferring to the treatment room. Every effort is also usually made to minimize patient and applicator movements, so that the dosimetry performed on treatment planning radiographs matches patient and applicator positions during the subsequent treatments.

Some radiologists suggest volumetric assessment of OARs as a better and more complete representation of doses to OARs $[5,9,10]$. Recently, a comparative study of OARs between 2D orthogonal films based planning and $3 \mathrm{D}$ based planning were discussed and shown that ICRU reference points doses underestimated D2cc volume dos-

Address for correspondence: Brahmacharimayum Arunkumar Sharma, PhD, Department of Radiotherapy, Received: 24.01 .11 Regional Cancer Centre, Regional Institute of Medical Sciences, Imphal 795 004, India, 
es for bladder, although no difference was found in rectum [11]. The dose to critical organs and toxicity is directly proportional in addition to the relation between the dose to critical organ and the measured dose at the respective points [12]. Most recently, a variation in Fletcher-Suit applicator geometry and the influence on critical structure were discussed in HDR-BT of cervical cancer $[13,14]$. In this paper we have evaluated variation in dose to rectum, bladder and point B dose of cervical cancer patient undergoing fractionated HDR-BT.

\section{Material and methods}

\section{Patient selection}

Twenty patients with histopathologically confirmed cervical cancer in different clinical stages were selected for this prospective study. Patients under study were treated with EBRT and HDR-BT between October 2009 and November 2010 in the Department of Radiotherapy, Regional Cancer Centre, Regional Institute of Medical Sciences, Imphal, India.

\section{Intracavitary radiotherapy (ICRT) applicator placement and markers}

The Fletcher-Suit applicators (Nucletron ${ }^{\circledR}$ ) were used with ovoid's: half ovoid (15 mm and $20 \mathrm{~mm}$ diameters) and full ovoid (20 mm diameter) with tandem angle of $15^{\circ}, 30^{\circ}$ and $45^{\circ}$. The combination of ovoid size and tandem angle were chosen according to patient's anatomy. Packing was done to avoid any shifting or changes in the geometry of the applicators placement and to prevent the relocation of the rectum and bladder. Foley balloon was inserted and filled with 7 cc of diluted urografin (30\% contrast: $70 \%$ water) and pulled down to be seated on the bladder trigone. Rectal probe have also been inserted in the rectum. All procedures were done without general or spinal anesthesia, after which, patients were shifted to conventional simulator room where dummies were inserted and orthogonal X-ray localization radiographs were taken. These images were digitized and planning was done on a treatment planning system (TPS). The measurement of dose for these patients to rectum, bladder and point $\mathrm{B}$ was completed in relation to dose at point $\mathrm{A}$.

\section{Brachytherapy planning}

Planning was done using the Plato Sunrise Treatment Planning System $\left(\right.$ Nucletron $\left.^{\circledR}\right)$. Dose in the range of 5 to 7.5 Gy in 2-5 fractions were generally prescribed to point A of the Manchester System using standard source loading pattern without optimization. However, all 20 patients under study were prescribed 7 Gy per fraction with a total number of three fractions each. In the planning process, rectal and bladder doses were planned to keep below $80 \%$ of dose to point A for each planned fraction. However, in a few cases either rectum or bladder was beyond $80 \%$ of point A. An attempt was made to keep bladder dose below the low dose rate (LDR) equivalent of $80 \mathrm{~Gy}$ and rectal dose below 75 Gy as suggested by the ABS [5]. Nine patients with a total fraction of 25 were selected randomly and each fraction was planned to evaluate variation in dose in rICRU, bICRU, B and A as well. In another study, 11 patients were selected randomly and after treatment of their first fraction were brought back to the simulator room for post orthogonal radiographs. These images were used for post treatment planning to evaluate any variation occurring before treatment. Half of the variation is considered as an unbiased estimation of transportation induced variation in a single fraction.

\section{Results}

The results of variation in dose in fractionated HDR-BT study of cervical cancer is shown in Table 1. Mean variation of dose due to fractionation along with their range in the percentage of point A were found as rICRU: 2.40 (0.50-6.38), bICRU: 4.29 (0.99-7.57), B: 0.79 (0.06-1.56) and A: 1.55 (0.06-3.24). In the other study, the variation in a single fraction due to the transportation process from simulator room to the treatment unit was found that the variation in relation to that of point $\mathrm{A}(\%)$ as rICRU: 0.70 (0.30-1.87), bICRU: 1.60 (0.82-3.49), B: 0.22 (0.05-0.66) and A: 0.58 (0.04-1.76).

\section{Discussion}

Maintaining the same HDR dose from one fraction to the next depends from both the tumour response and dose to the healthy tissues. The recommended HDR dose per fraction may vary by $\pm 0.25 \mathrm{~Gy}$ [5]. In case when a dose of 7 Gy to point $A$ is applied, the variation to point A should not be more than $3.57 \%$. Extra care is generally advised to ensure an adequate bladder and rectal packing when using high dose ( $\geq 7 \mathrm{~Gy})$. In case when the dose per fraction varies more than $3.57 \%$ at point $A$, the dose for the particular fraction is reduced and adjusted in the subsequent fraction or in additional fractions. In this study, the average variation of point $A$ due to the transportation process of about $0.58 \%$ (or $\pm 0.04 \mathrm{~Gy}$ ) was the most probable uncertainty in giving dose at point $\mathrm{A}$ at treatment. Thus, $0.58 \%$ less in the tolerance limit of A could be more appropriate

Table 1. The results of variation in dose in fractionated HDR-BT study of cervical cancer

\begin{tabular}{|c|c|c|c|c|}
\hline $\begin{array}{l}\text { Study } \\
\text { (number) }\end{array}$ & $\begin{array}{c}\text { rICRU } \\
\text { mean } \pm \sigma \text { (range) }\end{array}$ & $\begin{array}{c}\text { bICRU } \\
\text { mean } \pm \sigma \text { (range) }\end{array}$ & $\begin{array}{c}\mathrm{A} \\
\text { mean } \pm \sigma \text { (range) }\end{array}$ & $\begin{array}{c}\mathrm{B} \\
\text { mean } \pm \sigma \text { (range) }\end{array}$ \\
\hline $\begin{array}{l}\text { Variation in dose of individuals } \\
\text { in fractionation [9] }\end{array}$ & $\begin{array}{c}2.40 \pm 1.97 \\
(0.5-6.38)\end{array}$ & $\begin{array}{l}4.29 \pm 2.33 \\
(0.99-7.57)\end{array}$ & $\begin{array}{l}1.55 \pm 1.07 \\
(0.06-3.24)\end{array}$ & $\begin{array}{l}0.79 \pm 0.50 \\
(0.06-1.56)\end{array}$ \\
\hline $\begin{array}{l}\text { Variation in dose in a single fraction } \\
\text { of individual [11] }\end{array}$ & $\begin{array}{l}0.70 \pm 0.45 \\
(0.30-1.87)\end{array}$ & $\begin{array}{l}1.60 \pm 0.79 \\
(0.82-3.49)\end{array}$ & $\begin{array}{l}0.58 \pm 0.55 \\
(0.04-1.76)\end{array}$ & $\begin{array}{l}0.22 \pm 0.19 \\
(0.05-0.66)\end{array}$ \\
\hline
\end{tabular}


assumption i.e. instead of $3.57 \%$ of recommended limit of $\mathrm{A}$, as we considered $3.0 \%$ (i.e. 3.57-0.58) or variation limit of 0.21 Gy during brachytherapy planning. This reduction in recommended limit may not be applicable to IBU system because the transportation of a patient after taking orthogonal radiograph images was not involved. The variation of dose at OARs in the fractionation treatment of cancer of cervix in this present study is summarized in Fig. 1. The total variation of dose to point $A$ of an individual patient would be the sum of variation of dose in the fractionation and in a single fraction during the treatment process of ICRT. Therefore, the variation of dose to point A was obtained as $2.13 \%$ (i.e. $1.55+0.58$ ). This variation of dose to point $\mathrm{A}$ has been studied by many radiologists such as Corn et al. [15] and Koushik et al. [14], who presented the variation of $2 \%, 35 \%, 8 \%, 20 \%$ and $14 \%$. This is a wide range for the fact that some of the studies were completed with radium source and several with iridium and cesium sources. The other points such as rICRU, bICRU and B in this study were found as 3.09\%, 5.89\% and $1.01 \%$ of point A. An earlier report on rectal and bladder dose variation in an unfixed brachytherapy system by Pham [16] shown about $10 \%$ and $18 \%$. Recent studies on these critical points during low dose rate ICRT for cervical cancer by Koushik et al. [14] presents the variation of dose to rectal, bladder and point B as 3.5\%, 9.3\% and $2.0 \%$ of point $\mathrm{A}$. The smaller variation of bladder, rectum and point $B$ doses compared to other studies could have better reproducibility of the geometric relationships between the HDR-BT applicators and the critical structures.

\section{Conclusions}

The study of this evaluation of variation in dose of organs at risk in fractionated HDR-BT for cervical cancer was observed as follows: 1 ) average variation of the delivery dose per fraction of an individual patient was found well within the recommended limit, 2) the smaller variation in dose of organs at risk could have better reproducibility of geometric relationship between ICRT applicators and critical structures during the course of fractionated HDR-BT, 3) the variation of doses to organs at risk during the transportation of a patient from simulator room to treatment room after taking orthogonal radiograph images for treatment planning was very small, however not negligible for the increase of uncertainties of doses to critical organs.

\section{References}

1. Lanciano RM, Won M, Coia LR et al. Pretreatment and treatment factors associated with improved outcome in squamous cell carcinoma of the uterine cervix: a final report of the 1973 and 1978 patterns of care studies. Int J Radiat Oncol Biol Phys 1991; 20: 667-676.

2. Montana GS, Fowler WC, Varra MA et al. Carcinoma of the cervix, stage III: results of radiation therapy. Cancer 1986; 57: 148-154.

3. Perez CA, Breaux S, Madoc-Jones $\mathrm{H}$ et al. Radiation therapy alone in the treatment of carcinoma of the uterine cervix: I. Analysis of tumor recurrence. Cancer 1983; 51: 1393-1402.

4. Eifel PJ, Morris M, Oswald MJ. The influence of tumor size and growth habit on outcome of patients with FIGO stage IB squa-

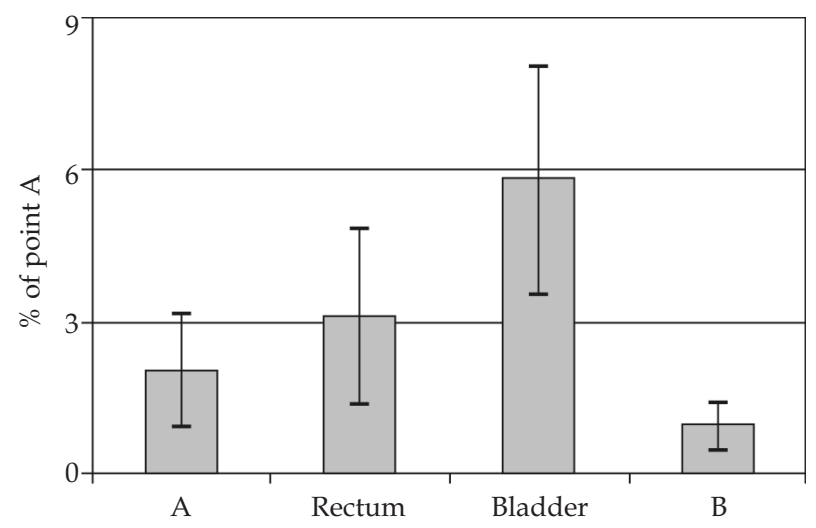

Fig. 1. Variation of dose of various OARs in the percentage of point $\mathrm{A}$ along with point $\mathrm{A}$ itself with their respective probable error

mous cell carcinoma of the uterine cervix. Int J Radiat Oncol Biol Phys 1993; 27: 127-128.

5. Nag S, Erickson B, Thomadsen B et al. The American Brachytherapy Society recommendations for High-Dose-Rate Brachytherapy for carcinoma of the cervix. Int J Radiat Oncol Biol Phys 2000; 48: 201-211.

6. ICRU. In: Chassagne D, Dutreix A, Almond P et al. ICRU Report No. 38: Dose and volume specification for reporting intracavitary therapy in gynecology. International Commission on Radiation Units and Measurements, Bethesda 1985.

7. Halperin EC, Perez CA, Brady LW (eds.). Principles and practice of radiation oncology. Lippincott William $\mathcal{E}$ Wilkins, Philadelphia 2008.

8. International Atomic Energy Agency. Implementation of microsource HDR in developing countries. IAEA-TECDOC1257, Vienna 2001.

9. Pelloski CE, Palmer M, Chronowski GM et al. Comparison between CT-based volumetric calculations and ICRU reference point estimates of radiation doses delivered to bladder and rectum during intracavitary radiotherapy for cervical cancer. Int J Radiat Oncol Biol Phys 2005; 62: 131-137.

10. Kim RY, Shen S, Duan J. Image-based three-dimensioned treatment planning of intracavitary brachytherapy for cancer of the cervix: Dose-volume histograms of the bladder, rectum, sigmoid-colon and small bowel. Brachytherapy 2007; 6: 187-194.

11. Tan YI, Choo BA, Lee KM. 2D to 3D Evaluation of Organs at Risk Doses in Intracavitary Brachytherapy for Cervical Cancer. J Contemp Brachyther 2010; 2: 37-43.

12. Stryker JA, Bartholomew M, Velkley DE et al. Bladder and rectal complications following radiotherapy for carcinoma cervix. Gyn Oncol 1988; 29: 1-11.

13. Palvolgyi J, Agyemang-Prempeh K. Inter-fractional variation in Fletcher-Suit applicator geometry (poster abstract). Central European Users Meeting: A Toolkit for Good Medical Practice in Brachytherapy, October 15-17, Budapest. J Contemp Brachyther 2009; 1: 179-180.

14. Koushik K, Bilimagga R, Rao N et al. Positional variation of applicators during low dose rate ICRT for cervical cancer: a prospective study. J Contemp Brachyther 2010; 2: 93-97.

15. Corn W, Galvin D, Soffen M et al. Positional stability of sources during LDR brachytherapy for cervical carcinoma. Int J Radiat Oncol Biol Phys 1993; 26: 513-518.

16. Pham T, Chen Y, Rouby E et al. Changes in HDR tandem and ovoid applicator positions during treatment in an unfixed brachytherapy system. Radiology 1998; 206: 525-531. 